\title{
Sistem Penyimpanan dan Pemrosesan Rekam Medis Terkait Standar Akreditasi Kriteria 8.4.3 di Puskesmas Jetis 1 Bantul
}

\author{
Rahmah Nindyakinanti ${ }^{1}$, Savitri Citra Budi ${ }^{2}$ \\ Program Studi Diploma III Rekam Medis Sekolah Vokasi Universitas Gadjah Mada ${ }^{1,2}$ \\ rahmah.nindyakinanti@mail.ugm.ac.id¹ ${ }^{1}$, savitri@ugm.ac.id²
}

\begin{abstract}
ABSTRAK
Latar Belakang: Puskesmas wajib dilakukan penilaian akreditasi setiap tiga tahun sekali. Perlu adanya upaya evaluasi terhadap kegiatan persiapan akreditasi yang telah dilakukan oleh Puskesmas agar lebih siap menghadapi penilaian akreditasi berikutnya. Berdasarkan hasil pengabdian kerja yang peneliti lakukan pada bulan Agustus 2015 di Puskesmas Jetis 1 Bantul, hampir setiap hari terjadi missfile di tempat penyimpanan rekam medis.
\end{abstract}

Tujuan Penelitian: Penelitian ini bertujuan untuk mengetahui sistem penyimpanan dan pemrosesan rekam medis terkait standar akreditasi kriteria 8.4.3 di Puskesmas Jetis 1 Bantul berdasarkan lima unsur manajemen yaitu men, materials, methods, machines, and money.

Metodologi Penelitian: Jenis penelitian ini adalah deskriptif kualitatif dan rancangan fenomenologi.

Hasil: Kompetensi dan jumlah petugas rekam medis yang tersedia belum memenuhi syarat. Surat Keputusan (SK) tentang Pengelolaan Rekam Medis dan Standar Operasional Prosedur (SOP) tentang Penyimpanan Rekam Medis tidak sesuai dengan format penyusunan dokumen akreditasi FKTP tahun 2015. Pelaksanaan kegiatan identifikasi pasien yang dilakukan oleh petugas rekam medis tidak sesuai dengan urutan kerja SOP. Formulir identitas pasien belum mengumpulkan data secara efektif dan efisien. Tidak terdapat prosedur tetap terkait dengan kegiatan pengkodean keluarga. Tracer tidak memuat nama pasien dan tujuan rekam medis dikeluarkan. Petugas tidak melakukan analisis kelengkapan rekam medis. Penentuan masa simpan berkas dan penyusutan tidak seimbang dengan luas tempat penyimpanan.

Kesimpulan: Sistem penyimpanan dan pemrosesan rekam medis terkait standar akreditasi kriteria 8.4.3 di Puskesmas Jetis 1 Bantul berdasarkan unsur manajemen men, materials, dan methods belum sesuai.

Kata Kunci: Akreditasi Puskesmas, Unsur Manajemen, Penyimpanan Rekam Medis.

\begin{abstract}
Background: Primary health center must be conducted of accreditation assesment every three years. Needed for an evaluation of the accreditation preparatory activities that has been done by the primary health center to be better prepared for the next accreditation assessment. Based on the results of work dedication that researchers do in August 2015 in Puskesmas Jetis 1 Bantul, almost every day there are missfiles in storage of medical records.

Objective: This reserach aims to know about storage system and medical records processing related to accreditation standards of criteria 8.4 .3 in Puskesmas Jetis 1 Bantul based on the five element management of men, materials, method, machines, and money.

Methods: This type of research is descriptive with a qualitative approach and phenomenal design.

Results: Competence and number of medical records practitioner are not accordanced. SK about how to organize medical records and SOP about archaiving medical recors is not accordance. The implementation of patients identification is not accordance with the fixed procedure that have been determined. Form design of patient's identity is not good because it's not able to gather data effectively and efficiently. There is no fixed procedure about coding of family. Tracer don't contain data of the patient's name and destination of the medical record. The medical records practitioner didn't do analysis of the completeness of medical record accordance to the specified fixed procedure. The shelf life of the medical records active and the implementation of the medical records depreciation is not balanced with the storage space available. Conclusion: Storage system and medical records processing related to accreditation standard of criteria 8.4.3 in Puskesmas Jetis 1 Bantul based on element management of men, materials, and the method is not appropriate.
\end{abstract}

Keywords: Accreditation of Puskesmas, Element of Management, Medical Record Storage 


\section{PENDAHULUAN}

Sistem penyimpanan rekam medis merupakan salah satu kriteria penilaian akreditasi puskesmas yang terdapat pada Peraturan Menteri Kesehatan Nomor 46 tahun 2015 tentang Akreditasi Puskesmas, Klinik Pratama, Tempat Praktik Mandiri Dokter, dan Tempat Praktik Mandiri Dokter Gigi. Kriteria yang memuat penilaian tentang sistem penyimpanan rekam medis adalah kriteria 8.4.3 yaitu adanya sistem yang memandu penyimpanan dan pemrosesan rekam medis. Berdasarkan hasil pengabdian kerja yang peneliti lakukan pada bulan Agustus 2015, hampir setiap hari terjadi missfile di tempat penyimpanan rekam medis Puskesmas Jetis 1 Bantul.

Berdasarkan Peraturan Menteri Kesehatan Nomor 46 tahun 2015 tentang Akreditasi Puskesmas, Klinik Pratama, Tempat Praktik Mandiri Dokter, dan Tempat Praktik Mandiri Dokter Gigi disebutkan bahwa puskesmas, klinik pratama, tempat praktik mandiri dokter, dan tempat praktik mandiri dokter gigi wajib terakreditasi setiap 3 (tiga) tahun. Hal ini menunjukkan bahwa akreditasi puskesmas merupakan suatu mekanisme yang digunakan untuk mengukur mutu pelayanan di puskesmas dan menjaga mutu pelayanan secara berkesinambungan, oleh karena itu perlu adanya upaya evaluasi kegiatan persiapan akreditasi yang telah dilakukan agar puskesmas dapat lebih siap menghadapi penilaian akreditasi selanjutnya. Berdasarkan uraian tersebut, peneliti tertarik untuk melakukan penelitian dengan judul "Sistem Penyimpanan dan Pemrosesan Rekam Medis terkait Standar Akreditasi Kriteria 8.4.3 di Puskesmas Jetis 1 Bantul". Rumusan masalah dalam penelitian ini adalah "Bagaimana sistem penyimpanan dan pemrosesan rekam medis terkait standar akreditasi kriteria 8.4.3 di Puskesmas Jetis 1 Bantul?". Penelitian ini bertujuan untuk mengetahui sistem penyimpanan dan pemrosesan rekam medis terkait standar akreditasi kriteria 8.4.3 di Puskesmas Jetis 1 Bantul berdasarkan lima unsur manajemen yaitu men, materials, methods, machines, and money. Penelitian ini bermanfaat sebagai bahan masukan dan evaluasi Puskesmas Jetis 1 Bantul terkait sistem penyimpanan dan pemrosesan rekam medis sehingga Puskesmas Jetis 1 Bantul dapat lebih siap menghadapi penilaian akreditasi puskesmas berikutnya.

\section{METODE}

Jenis penelitian yang digunakan dalam penelitian ini adalah deskriptif dengan pendekatan kualitatif. Subjek dalam penelitian ini terdiri atas tiga anggota kelompok kerja pelayanan klinis dan tiga petugas rekam medis. Objek dalam penelitian ini adalah kegiatan yang telah dilakukan oleh Puskesmas Jetis 1 Bantul pada sistem penyimpanan dan pemrosesan rekam medis terkait standar akreditasi kriteria 8.4.3 berdasarkan unsur manajemen men, materials, methods, machines, and money. Teknik pengambilan data yang digunakan adalah wawancara, observasi, dan studi dokumentasi.

\section{HASIL DAN PEMBAHASAN}

1. Unsur Manajemen Men

Sistem penyimpanan dan pemrosesan rekam medis terkait standar akreditasi kriteria 8.4.3 di Puskesmas Jetis 1 Bantul berdasarkan unsur manajemen men adalah membentuk tim persiapan akreditasi. Tim persiapan akreditasi puskesmas terdiri atas tim penanggung jawab mutu dan tiga kelompok kerja yaitu kelompok kerja administrasi manajemen, kelompok kerja Upaya Kesehatan Masyarakat (UKM), dan kelompok kerja pelayanan klinis atau Upaya Kesehatan Perorangan (UKP). Di antara tiga kelompok kerja tersebut, persiapan akreditasi pada sistem penyimpanan dan pemrosesan rekam medis terkait standar akreditasi kriteria 8.4.3 menjadi tanggung jawab kelompok kerja pelayanan klinis atau Upaya Kesehatan Perorangan (UKP).

Hal tersebut sesuai dengan Peraturan Menteri Kesehatan Nomor 46 tahun 2015 tentang Akreditasi Puskesmas, Klinik Pratama, Tempat Praktik Mandiri Dokter, dan Tempat Praktik Mandiri Dokter Gigi yang menyebutkan bahwa "Pimpinan puskesmas menetapkan penanggung jawab manajemen mutu yang bertanggung jawab untuk mengkoordinasikan memonitor kegiatan peningkatan mutu dan kinerja puskesmas dan membudayakan perbaikan kinerja yang berkesinambungan secara konsisten 
dengan tata nilai, visi, misi, dan tujuan puskesmas".

Puskesmas Jetis 1 Bantul membutuhkan empat petugas lulusan Diploma Tiga Rekam Medis namun saat ini petugas lulusan Diploma Tiga Rekam Medis yang terdapat di Puskesmas Jetis 1 Bantul hanyaberjumlah satu orang. Oleh karena itu untuk menunjang pelayanan rekam medis, Kepala Puskesmas memberikan kewenangan kepada sebelas petugas non rekam medis untuk melakukan kegiatan rekam medis melalui proses kredensial. Puskesmas Jetis 1 Bantul juga memberikan on the job training kepada sebelas petugas non rekam medis. Pelayanan rekam medis di Puskesmas Jetis 1 Bantul yang tidak dilakukan sepenuhnya oleh lulusan Diploma Tuga Rekam Medis menunjukkan bahwa hal tersebut tidak sesuai dengan Peraturan Menteri Kesehatan Nomor 55 tahun 2013 tentang Penyelenggaraan Pekerjaan Perekam Medis yang menyebutkan bahwa "Perekam medis adalah seorang yang telah lulus pendidikan rekam medis dan informasi kesehatan sesuai ketentuan peraturan perundang- undangan".

\section{Unsur Manajemen Materials}

Sistem penyimpanan dan pemrosesan rekam medis berdasarkan unsur manajemen materials adalah dokumen akreditasi yang dibuat oleh Puskesmas Jetis 1 Bantul terkait standar akreditasi kriteria 8.4.3 dan format penyusunan dokumen akreditasi yang digunakan. Terkait dnegan upaya pemenuhan standar akreditasi kriteria 8.4.3, Puskesmas Jetis 1 Bantul membuat dokumen akreditasi Surat Keputusan (SK) tentang Pengelolaan Rekam Medis dan Standar Operasional Prosedur (SOP) tentang Penyimpanan Rekam Medis. Surat Keputusan (SK) tentang Pengelolaan Rekam Medis sudah memuat semua kebijakan yang dibutuhkan pada masing-masing elemen penilaian yang terdapat pada kriteria 8.4.3 tentang sistem penyimpanan dan pemrosesan rekam medis. Hal ini menunjukkan bahwa dokumen akreditasi yang dibuat oleh Pukesmas Jetis 1 Bantul terkait standar akrediasi kriteria 8.4.3 sudah sesuai dengan Instrumen Penilaian Akreditasi Puskesmas tahun 2015 yang menyebutkan bahwa "Dokumen telusur yang terdapat pada standar akreditasi kriteria 8.4.3 adalah SK pelayanan rekam medis dan metode identifikasi; SK tentang sistem pengkodean, penyimpanan, dokumentasi rekam medis; SK dan SOP penyimpanan rekam medis".

Berdasarkan analisis yang peneliti lakukan pada Surat Keputusan (SK) tentang Pengelolaan Rekam Medis dan Standar Operasional Prosedur (SOP) tentang Penyimpanan Rekam Medis, diketahui bahwa format penyusunan dokumen akreditasi yang tersebut tidak sesuai dengan Pedoman Penyusunan Dokumen Akreditasi FKTP tahun 2015. Ketidaksesuaian penyusunan Surat Keputusan (SK) tentang Pengelolaan Rekam Medis terletak pada beberapa bagian yaitu pembukaan, kaki, dan penandatanganan. Pada bagian pembukaan ketidaksesuaian terdapat pada penulisan nomor yang tidak menggunakan huruf kapital semua, tidak terdapat pernyataan "Dengan Rahmat Tuhan Yang Maha Esa", dan penulisan jabatan pembuat keputusan tidak diakhiri dengan tanda koma (,). Pada bagian kaki ketidaksesuaian terdapat pada penulisan nama jabatan yang tidak diakhiri dengan tanda koma (,). Pada bagian penandatanganan ketidaksesuaian terdapat pada penulisan Kepala Fasilitas Kesehatan Tingkat Pertama (FKTP) yang disertai dengan gelar.

Ketidaksesuaian penyusunan Standar Prosedur Operasional (SOP) tentang Sistem Penyimpanan Rekam Medis terletak pada bagian isi terkait dengan kebijakan Kepala Fasilitas Kesehatan Tingkat Pertama (FKTP). Pembuatan Standar Prosedur Operasional (SOP) tentang Sistem Penyimpanan Rekam Medis tidak mengacu pada Surat Keputusan (SK) yang memuat kebijakan tentang penyimpanan rekam medis yaitu mengacu pada Surat Keputusan (SK) tentang Proses Pendaftaran Pasien.

\section{Unsur Manajemen Methods}

Sistem penyimpanan dan pemrosesan rekam medis terkait standar akreditasi 
kriteria 8.4.3 berdasarkan unsur manajemen methods dibedakan menjadi empat yaitu pembuatan dokumen akreditasi, evaluasi kegiatan persiapan akreditasi, koordinasi kelompok kerja pelayanan klinis, dan pelaksanaan elemen penilaian pada kriteria 8.4.3 tentang sistem penyimpanan dan pemrosesan rekam medis. Dokumen akreditasi tentang sistem penyimpanan dan pemrosesan rekam medis terkait standar akreditasi kriteria 8.4.3 dibuat dengan beberapa tahap, diantaranya adalah identifikasi kebutuhan dokumen akreditasi, pembagian tugas kepada petugas rekam medis, koreksi dokumen, penetapan dokumen oleh Kepala Puskesmas, pemberian nomor dokumen, dan sosialisasi dokumen akreditasi kepada bagian rekam medis. Hal ini sesuai dengan tahap pembuatan dokumen akreditasi dalam Pedoman Penyusunan Dokumen Akreditasi FKTP tahun 2015.

Upaya evaluasi kegiatan persipan akreditasi yang dilakukan oleh Puskesmas Jetis 1 Bantul adalah dengan melakukan self assesment dan audit internal. Self assesment dilakukan oleh kelompok kerja pelayanan klinis atau Upaya Kesehatan Perorangan (UKP) untuk mengetahui sejauh mana dokumen akreditasi pada sistem penyimpanan dan pemrosesan rekam medis terkait standar akreditasi 8.4.3 telah terpenuhi. Audit internal di bagian rekam medis dilakukan oleh petugas laboratorium yaitu untuk menilai kesesuaian pelayanan yang dilakukan oleh petugas rekam medis dengan Standar Operasional Prosedur (SOP) yang telah ditetapkan. Hal ini sesuai dengan Azwar (2010) yang menyebutkan bahwa "Metode pengawasan dapat dilakukan melalui laporan khusus dan hasil analisa yang dilakukan terhadap laporan khusus, melalui data statistik yang dikumpulkan yang menyangkut berbagai aspek kegiatan organisasi, melalui observasi personal yang dilakukan oleh pimpinan (personal observation) atau orang-orang tertentu (control through key personnel), dan audit internal".

Koordinasi yang dilakukan oleh kelompok kerja pelayanan klinis atau
Upaya Kesehatan Peroangan (UKP) dalam melakukan kegiatan persiapan akreditasi terdiri atas dua macam yaitu koordinasi formal dan informal. Koordinasi formal dilakukan melalui kegiatan pendampingan dengan tim pendamping akreditasi dalam pertemuan resmi yang kegiatannya didokumentasikan dalam notulen. Koordinasi informal dilakukan antar anggota kelompok kerja pelayanan klinis atau Upaya Kesehatan Perorangan (UKP) Puskesmas Jetis 1 Bantul, baik melalui pertemuan langsung maupun tidak langsung dengan bantuan media sosial. Hal ini sesuai dengan Azwar (2010) yang menyebutkan bahwa "Jika ditinjau dari suasana atau lingkungan, komunikasi dibedakan menjadi dua yaitu komunikasi formal yang dilakukan dalam suasana resmi misalnya pertemuan rapat dan komunikasi informal yang dilakukan dalam suasana tidak resmi misanya ketika sedang berjalan berduaan, atau sedang berdarmawisata".

Pelaksanaan elemen penilaian pada kriteria 8.4.3 tentang sistem penyimpanan dan pemrosesan rekam medis terkait sistem identifikasi pasien adalah belum sepenuhnya sesuai dengan urutan kerja pada Standar Prosedur Operasional (SOP) tentangIdentifikasi Pasien. Petugas merasakan kendala dalam pengumpulan data identitas pasien yaitu banyak pasien yang tidak melengkapi data identitas pasien terutama pada data tanggal lahir pasien. Hal ini tidak sesuai dengan Huffman (1994) yang menyebutkan "Perancangan formulir yang buruk dapat menyebabkan pengumpulan data menjadi tidak lengkap, pendokumentasian yang lamban, informasi yang salah, pekerjaan yang dilakukan dua kali, dan kesalahankesalahan lain. Formulir harus dievaluasi secara teratur untuk memastikan bahwa mereka mudah digunakan, mampu mengumpulkan semua data yang dibutuhkan, menghilangkan pengumpulan data yang tidak diperlukan, dan medis tidak memisahkan rekam medis anggota keluarga yang sudah menikah menjadi family folder baru. 
Hal ini tidak sesuai dengan Peraturan Dalam Negeri Nomor 52 tahun 2011 tentang Standar Operasional Prosedur di Lingkungan Pemerintah Provinsi dan Kabupaten/ Kota pada pasal 9 ayat (2), yang menyebutkan bahwa "Kegiatan yang memerlukan SOP memenuhi kriteria yaitu kegiatannya dilaksanakan secara rutin atau berulang-ulang, menghasilkan output tertentu, dan kegiatannya melibatkan sekurang-kurangnya 2 (dua) orang/ pihak". Hal ini juga tidak sesuai dengan Huffman (1994) yang menyebutkan bahwa "Melalui perceraian, seorang spouse bisa berubah menjadi kepala dari keluarga yang lain. Seorang anak bisa berubah menjadi spouse atau kepala keluarga setelah menikah. Pada keadaan ini, nomor keluarga yang baru harus diterbitkan dan menghasilkan sebuah catatan yang baru". Berikut adalah contoh pelaksanaan pengkodean keluarga di Puskesmas Jetis 1 Bantul

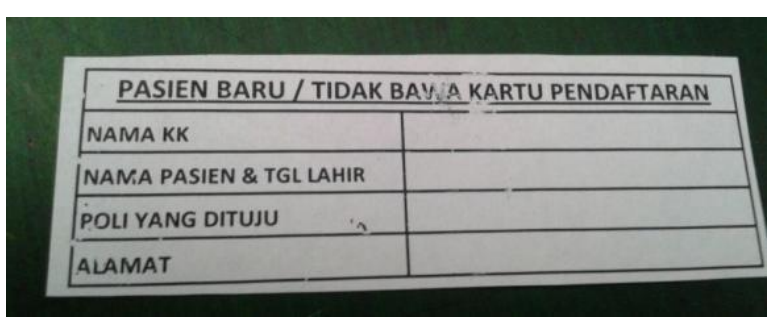

Gambar 1. Formulir Identitas Pasien

Pelaksanaan kegiatan pada elemen penilaian pada kriteria 8.4.3 tentang sistem penyimpanan dan pemrosesan rekam medis terkait pengkodean keluarga adalah Puskesmas Jetis 1 Bantul tidak memiliki Standar Operasional Prosedur (SOP) terkait kegiatan pengkodean keluarga.

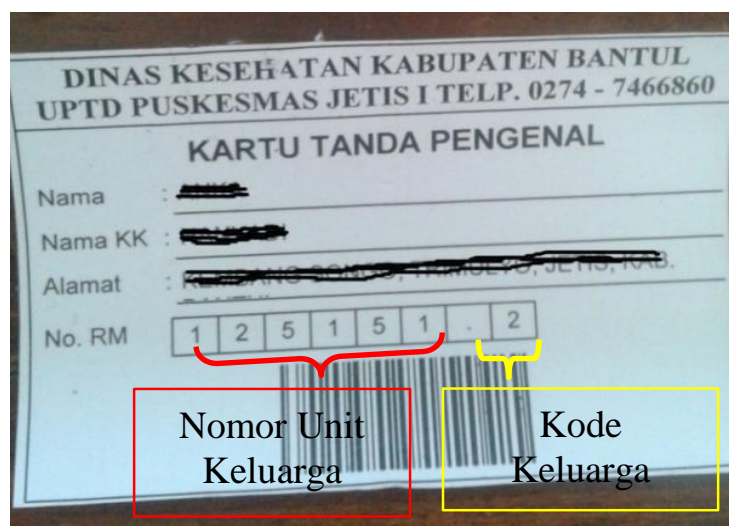

Gambar 2. Pelaksanaan Kode Keluarga
Petugas rekam medis merasakan kendala dalam kegiatan penyimpanan rekam medis yaitu terjadinya missfile. Petugas rekam medis sudah melakukan upaya mengurangi missfile dengan menggunakan tracer. Tracer yang digunakan memuat informasi berupa tanggal rekam medis dikeluarkan, nomor rekam medis, dan nama dusun tempat tinggal pasien. Hal ini tidak sesuai dengan WHO (2006) karena tracer yang digunakan di Puskesmas Jetis 1 Bantul tidak memuat data berupa nama pasien dan tujuan rekam medis dikeluarkan dari tempat penyimpanan. Di dalam WHO (2006) disebutkan bahwa "Jenis outguide atau tracer yang baik adalah dalam bentuk kartu, bisanya ukurannya sama atau sedikit lebih besar dari rekam medis, dan harus tercantum nama pasien, nomor rekam medis, tujuan rekam medis; dan tanggal keluar dari tempat penyimpanan". Berikut adalah tracer yang digunakan di Puskesmas Jetus 1 Bantul:

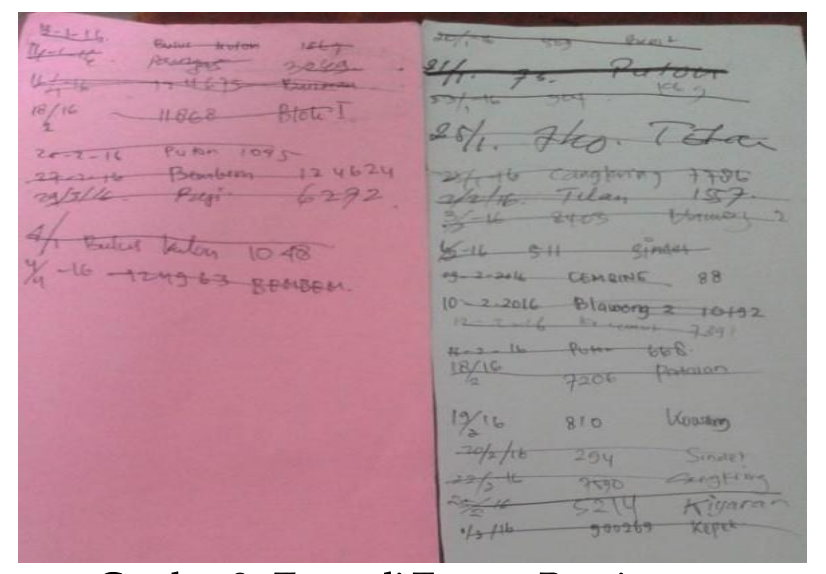

Gambar 3. Tracer di Tempat Penyimpanan Rekam Medis

Pelaksanaan kegiatan elemen penilaian pada kriteria 8.4.3 tentang sistem penyimpnana dan pemrosesan. Pelaksanaan kegiatan elemen penilaian pada kriteria 8.4.3 tentang sistem penyimpanan dan pemrosesan rekam medis terkait penyimpanan rekam medis adalah pelaksanaan penyimpanan rekam medis sudah sesuai dengan Standar Operasional Prosedur (SOP) tentang Penyimpanan Rekam Medis. rekam medis terkait dokumentasi rekam medis adalah belum sepenuhnya sesuai dengan Standar 
Operasional Prosedur (SOP) terkait dokumentasi rekam medis yang ditetapkan di Puskesmas Jetis 1 Bantul yaitu SOP tentang Menilai Kelengkapan dan Ketetapan Rekam Medis. Petugas rekam medis di Puskesmas Jetis 1 Bantul telah melakukan analisis kelengkapan rekam medis pada bagian Subjek Objek Assesment Plan (SOAP) dokter, Subjek Objek Assesment Plan (SOAP) perawat, paraf dokter, dan paraf perawat.

Hal ini tidak sesuai dengan Standar Operasional prosedur (SOP) nomor SOP/PD/11 tentang Menilai Kelengkapan dan Ketetapan Rekam Medis karena petugas rekam medis tidak melakukan analisis kelengkapan terhadap pengisian identitas, nama pemeriksa, tanggal atau hari pemeriksaan, dan terapi. Di dalam SOP tersebut disebutkan bahwa "Prosedur dalam menilai kelengkapan rekam medis adalah petugas memeriksa kelengkapan dan ketetapan isi rekam medis meliputi identitas, SOAP perawat, SOAP dokter, tanda tangan dan nama pemeriksa, tanggal atau hari pemeriksaan, dan terapi".

Pelaksanaan elemen penilaian pada kriteria 8.4.3 tentang sistem penyimpanan dan pemrosesan rekam medis terkait sistem retensi adalah Puskesmas Jetis 1 Bantul menetapkan kebijakan masa simpan rekam medis aktif selama lima tahun. Petugas rekam medis telah melakukan penyusutan rekam medis satu kali menjelang penilaian akreditasi. Petugas rekam medis mengaku kegiatan penyusutan yang dilakukan belum maksimal maksimal dan masih mengalami kendala sesaknya berkas rekam medis di tempat penyimpanan. Hal ini tidak sesuai dengan Huffman (1994) yang menyebutkan bahwa "Secara praktis kriteria utama penentuan inaktif catatan adalah luas tempat yang tersedia di departemen untuk penyimpanan catatan medis yang lebih baru secara efisien. Kalau tidak ada lagi tempat untuk penyimpanan catatan aktif, maka harus diusahakan untuk secara sistematis menginaktifkan catatan dengan kecepatan sama dengan penambahan catatan baru".
4. Unsur Manajemen Machines

Sistem penyimpanan dan pemrosesan rekam medis di Puskesmas Jetis 1 Bantul berdasarkan unsur manajemen machines mengenai peralatan yang digunakan untuk melaksanakan kegiatan pelayanan elemen penilaian pada kriteria 8.4.3 tentang sistem penyimpanan dan pemrosesan rekam medis diantaranya adalah terdiri atas peralatan elektronik dan bukan elektronik. Peralatan elektronik yang digunakan terdiri atas komputer, printer, barcode scanner, dan microphone. Peralatan bukan elektronik yang digunakan diantaranya adalah alat tulis kantor, formulir pendaftaran pasien baru, buku register pendaftaran pasien, alat penyimpan berkas yang berupa rak kayu dan boxfile, dan tracer.

Hal ini sesuai dengan Gie (2000) yang menyebutkan bahwa "Perbekalan tata usaha adalah semua perbekalan ataupun peralatan yang berupa barang- barang kantor yang diperlukan untuk menunjang lancarnya pekerjaan kantor dalam usaha pencapaian tujuan organisasi".

\section{Unsur Manajemen Money}

Sistem penyimpanan dan pemrosesan rekam medis terkait standar akreditasi kriteria 8.4.3 di Puskesmas Jetis 1 Bantul pada unsur manajemen money adalah Puskesmas Jetis 1 Bantul merupakan puskesmas yang berbentuk Badan Layanan Umum Daerah (BLUD) sehingga seluruh kebutuhan akreditasi puskesmas dibiayai oleh puskesmas sendiri. Pendapatan Puskesmas Jetis 1 Bantul bersumber dari Anggaran Pendapatan dan Belanja Daerah (APBD) Kota/ Kabupaten, Anggaran Pendapatan dan Belanja Daerah (APBD) Provinsi, jasa pelayanan berupa kapitasi Badan Penyelenggaran Jaminan Sosial (BPJS), hibah, dan hasil kerjasama dengan pihak lain seperti pendapatan dari mahasiswa praktek.

Hal ini sesuai dengan Peraturan Menteri Dalam Negeri Nomor 61 tahun 2007 tentang Pedoman Teknis Pengelolaan Keuangan Badan Layanan Umum Daerah yang menyebutkan bahwa "Pendapatan Badan Layanan Umum Daerah (BLUD) 
dapat bersumber dari jasa layanan; hibah; hasil kerjasama dengan pihak lain; APBD; APBN; dan lain-lain pendapatan BLUD yang sah".

\section{PENUTUP}

1. Kesimpulan

Sistem penyimpanan dan pemrosesan rekam medis terkait standar akreditasi kriteria 8.4.3 berdasarkan unsur manajemen men adalah Puskesmas Jetis 1 Bantul membentuk tim persiapan akreditasi dan melakukan kredensial serta on the job training kepada sebelas petugas non rekam medis.

Sistem penyimpanan dan pemrosesan rekam medis terkait standar akreditasi kriteria 8.4.3 berdasarkan unsur manajemen materials adalah terdapat ketidaksesuaian terhadap format penyusunan dokumen akreditasi terkait kriteria 8.4.3 yang dibuat oleh Puskesmas Jetis 1 Bantul yaitu Surat Keputusan (SK) tentang Pengelolaan Rekam Medis dan Standar Operasional Prosedur (SOP) tentang Penyimpanan Rekam Medis.

Sistem penyimpanan dan pemrosesan rekam medis terkait standar akreditasi kriteria 8.4.3 berdasarkan unsur manajemen methods adalah dokumen akreditasi dibuat dengan beberapa tahap, evaluasi kegiatan persiapan dilakukan dengan self assesment dan audit internal, koordinasi persiapan akreditasi dilakukan secara formal dan informal, pelaksanaan identifikasi pasien terkendala dengan banyaknya pasien yang tidak melengkapi formulir identitas pasien, tidak terdapat prosedur tetap terkait kegiatan pengkodean keluarga, tracer yang digunakan tidak memuat informasi berupa nama pasien dan tujuan rekam medis, petugas rekam medis baru melakukan analisis kelengkapan rekam medis pada bagian Subjek Objek Assesment Plan (SOAP) dokter, Subjek Objek Assesment Plan (SOAP) perawat, dan paraf, kegiatan penyusutan rekam medis telah dilakukan sekali namun petugas masih merasakan kendala yaitu sesaknya berkas rekam medis di dalam rak penyimpanan.

Sistem penyimpanan dan pemrosesan rekam medis terkait standar akreditasi kriteria 8.4.3 berdasarkan unsur manajemen machines yang digunakan untuk melaksanakan kegiatan elemen penilaian pada kriteria tersebut adalah menggunakan komputer, printer, barcode scanner, microphone, alat tulis kantor, formulir identitas pasien, buku register pendaftaran pasien, alat penyimpan berkas berupa rak kayu dan boxfile, dan tracer.

Sistem penyimpanan dan pemrosesan rekam medis terkait standar akreditasi kriteria 8.4.3 berdasarkan unsur manajemen moneyadalah Puskesmas Jetis 1 Bantul sudah berbentuk Badan Layanan Umum Daerah sehingga seluruh kebutuhan terkait dengan akreditasi menggunakan anggaran dari puskesmas sendiri.

2. Saran

a. Memenuhi kebutuhan petugas Diploma Tiga Rekam Medis sesuai dengan jumlah yang dibutuhkan oleh Puskesmas Jetis 1 Bantul.

b. Melakukan evaluasi terhadap Surat Keputusan tentang Pengelolaan Rekam Medis pada bagian pembukaan, kaki, dan penandatanganan dan melakukan evaluasi terhadap Standar Operasional Prosedur (SOP) tentang Penyimpanan Rekam Medis pada bagian isi.

c. Melakukan evaluasi terhadap urutan kerja pada Standar Operasional Prosedur (SOP) tentang Identifikasi Pasien dan disesuaikan dengan urutan kerja yang dilakukan oleh petugas rekam medis dalam melakukan identifikasi pasien.

d. Melakukan evaluasi terhadap desain formulir identitas pasien agar dapat mengumpulkan data pasien secara efektif dan efisien.

e. Membuat Standar Operasional Prosedur (SOP) terkait dengan kegiatan pengkodean keluarga.

f. Menambahkan data berupa nama pasien dan tujuan rekam medis dikeluarkan dari tempat penyimpanan pada tracer yang digunakan.

g. Melakukan analisis kelengkapan rekam medis sesuai dengan Standar Operasional Prosedur (SOP) yang telah ditetapkan yaitu SOP tentang Menilai 
Kelengkapan dan Ketetapan Rekam Medis.

h. Melakukan evaluasi terhadap penentuan masa simpan rekam medis aktif dan pelaksanaan penyusutan rekam medis yang disesuaikan dengan luas tempat penyimpanan rekam medis yang tersedia.

\section{DAFTAR PUSTAKA}

Azwar, A. (2010) Pengantar Administrasi Kesehatan. Jakarta: Binarupa Aksara

BUK. (2015) Pedoman Penyusunan Dokumen Akreditasi Fasilitas Kesehatan Tingkat Pertama Jakarta: Direktorat Jenderal Bina Upaya Kesehatan Daerah.

Gie, The Liang (2000) Administrasi Perkantoran Modern. Yogyakarta: Liberty

Huffman, E.K. (1994) Helath Information Management. Illinois: Physicians Record Company

Peraturan Menteri Kesehatan Republik Indonesia Nomor 46 Tahun 2015 Tentang Akreditasi Puskesmas, Klinik Pratama, Tempat Praktik Mandiri Dokter, Dan Tempat Praktik Mandiri Dokter Gigi. www.buk.kemkes.go.id. Diakses tanggal 14 Januari 2016.

Peraturan Menteri Kesehatan Republik Indonesia Nomor 55 Tahun 2013 Tentang Penyelenggaraan Pekerjaan Perekam Medis. $\quad$ www.hukor.kemkes.go.id. Diakses tanggal 27 Maret 2016.

Peraturan Dalam Negeri Nomor 52 Tahun 2011 tentang Standar Operasional Prosedur di Lingkungan Pemerintah Provinsi dan Kabupaten/Kota. www.jdih.kemenkeu.go.id. Diakses tanggal 25 Mei 2016.

Peraturan Menteri Dalam Negeri Nomor 61 Tahun 2007 tentang Pedoman Teknis Pengelolaan Keuangan Badan Layanan Umum Daerah. www.kemendagri.go.id. Diakses tanggal 15 April 2016.

WHO. (2006) Medical Records Manual: $A$ Guide For Developing Countries. Manila: WHO Regional Office for The Western Pacific. 